\title{
El Theos de la teo-logía ante el Foro Social Mundial*
}

\section{Jon Sobrino \\ Centro de Reflexión Teológica San Salvador}

El lema "otro mundo es posible" expresa una esperanza, pero tiene otro presupuesto obvio y más fundamental: "otro mundo es necesario". Para verlo así es necesaria la honradez con lo real, y para sanarlo y humanizarlo es necesario compasión y compromiso. En esta ponencia quisiera analizar lo que la teo-logía puede aportar a esta esperanza y a este compromiso.

Las cosas que voy a decir son conocidas, pero vuelvo sobre ellas pues nunca hay que darlas por supuesto. $Y$ aunque no sea habitual en este tipo de foros, trataré de hacerlo reflexionando e insistiendo explícitamente en el Theos de la teo-logía. De esta forma, espero, se otorgará mayor seriedad al discurso de "un mundo otro" desde la teología en cuanto tal.

\section{Dos reflexiones previas}

\subsection{Una confesión personal}

Si se me permite una palabra personal, mi interés principal en participar en este Foro es poder estar en África, y lo digo con respeto, humildad y agradecimiento. Casaldáliga acaba de escribir: "África, la shoa de nuestro tiempo". Y el economista Luis de Sebastián acaba de publicar un libro: "África, pecado de Europa". Es el horror y la iniquidad.

* E1 presente artículo es la reelaboración de una breve ponencia en el Foro Mundial de Teología, celebrado inmediatamente antes y en el contexto del Foro Social Mundial, en Nairobi, el 16 de enero de 2007. 
Pues bien, en Nairobi he podido visitar Kibera, 800 mil personas —algo así como la ciudad de San Salvador-, la favela más grande de Africa, con una letrina, infame, para cada 200 personas. Dicen que a veces hay que pagar unos centavos para usarla. Y que, en algunos lugares, tienen que esperar a la época de lluvia para poder limpiar las letrinas.

No me gusta empezar así por respeto a las personas que allí viven, y sobre todo por la veneración que me merece su indoblegable voluntad de ser. Pero sin hacer central la realidad de Kibera, amenaza el peligro de quedarnos con los modernos rascacielos del centro de la ciudad y con el magnífico estadio, la sede física del Foro Social Mundial, al que no pueden llegar los habitantes de Kibera por la lejanía y por el precio del pasaje en bus. Sin hacer de Kibera algo central, no creo que entendamos lo que está en juego en un Foro Social, y ciertamente en un Foro Mundial de Teología. No comprenderemos el Theos de la teología, ni para qué sirve.

Pero estando en África, me parece igualmente necesario hablar de gracia - lenguaje absolutamente paradójico y escandaloso. Ello sólo es posible a partir de experiencias reales. Y abundan. Voluntarios y religiosas en campos de refugiados de Bukavu comentan su asombro por la voluntad de vivir que tienen allí seres humanos, a los que les han quitado todo, hasta el nombre. Para mí, su existencia y su voluntad de vivir es "la santidad primordial". Y en un acto de máxima honradez, religiosas y voluntarios nos dicen también: "no se dan cuenta de cuánto recibimos de ellos y cómo nos salvan".

Kibera es lugar de realidaá y hace que ocurran realidades. Sus habitantes abren nuestros ojos, aun cuando pensamos que ya los tenemos abiertos. Mueven las entrañas a misericordia, aunque pensemos que ya nos dedicamos a trabajar por los pobres de este mundo. Y puede ser lugar de revelación: se puede hacer presente el misteryum fascinans et tremens. Y eso me parece muy importante, sobre todo si pensamos que sobre el misterio de Dios ya sabemos lo suficiente. O si pensamos que, a fin de cuentas, si de lo que se trata es de pensar sobre "otro mundo es posible", podemos ignorar a Dios sin pérdida mayor.

Kibera, por último, recuerda una tradición de la teología fácilmente silenciada, pero que asoma periódicamente en los que tiene la osadía de preguntarse por Dios en la historia real. " ¿Permanecen ustedes junto a Dios en la cruz, pobre, insultado, sin abrigo, sin pan?”, decía Bonhoeffer. “¿Estaban ustedes allí cuando crucificaron a mi Señor?", cantaban los negros esclavos de Estados Unidos. Muchos se lo han preguntado desde América Latina. Y sin preguntarse por ello, al menos desde la fe cristiana, más vale callar.

Y Kibera puede recordar otra tradición todavía más silenciada: en medio de esas cruces hay fuerza y espíritu, música, sonrisa, dignidad, tan difíciles de encontrar en lugares de abundancia. No se me ocurren mejores palabras que las que dije al principio: opthe, se dejó ver, apareció una indoblegable voluntad de ser. 
Para los teólogos, participar, aunque sea un poco, en ese mundo de pecado y de gracia me parece fundamental. En 2005, al organizar en El Salvador el XXV aniversario de Mons. Romero, insistí personalmente en una sola cosa: que viniese alguien de África. Y llegó un sacerdote del Congo.

\subsection{Por qué mencionar el Theos en el contexto de un Foro Social Mundial}

Para desear que "otro mundo es posible" y trabajar por ello no se necesita religión ni teología $-\mathrm{y}$ hubo épocas en que esto hubiera sido obstáculo más que ayuda. Pero hoy muchos intuyen, aun no siendo personas religiosas, que las religiones y las teologías puede aportar. De cerca o de lejos, lo han visto en las luchas del pastor Martin Luther King o del arzobispo Romero o del rector Ellacuría. Pero más en concreto, hay que preguntarse si en este foro de teo-logía interesa la explicitación del Theos. En otras palabras, ¿existe la convicción de que el Theos es útil para construir un "mundo otro"?

Aquí vamos a hablar del Theos de la tradición bỉblico-jesuánica, la cual está abierta, real y sinceramente, a otras tradiciones religiosas, como las africanas, sobre las que nos hablarán estos días, y sobre lo que diremos una palabra al final. Esa tradición ha llegado hasta nosotros historizada por Oscar Romero, Christophe Munzihirwa, Desmond Tutu, obispos conocidos, y por mujeres cuyos nombres son menos conocidos - entre nosotros en El Salvador Silvia, Ita, Maura. Y es el Theos presente en la fe y la esperanza de millones de seres humanos pobres. No sé a cabalidad quién es ese Dios para ellos, pero espero que, al menos analógicamente, ese Dios, de quienes no dan la vida por supuesto, sea el mismo Dios de quienes sí la damos.

Todavía a nivel introductorio, dos cosas quiero decir sobre ese Dios. La primera es que Dios "tiene contenidos", por decirlo de alguna manera. Es Abba, referente personal en quien depositar confianza, y ofrece un reino, referente social de los pueblos que esperan justicia. El Theos es bueno para los seres humanos, como personas y pueblos. Es amor con predilección hacia los oprimidos. Es el Padre de Jesús, quien nos hace presente "los contenidos de Dios". Y es el Dios que envía su Espíritu, el cual, "pasando por Jesús", mueve a historizar los contenidos fundamentales de Dios. Se hace presente en testigos, y a través de ellos se puede barruntar su utopía para la creación, y los caminos para cambiarla, liberarla, redimirla, humanizarla. Es el Dios de lo concreto, el Dios que mantiene la esperanza de que "otro mundo es posible".

Pero el Theos es también "misterio santo", que decía K. Rahner. Y para enfatizarlo añadía que "el misterio permanece misterio eternamente". Ésta no suele ser reflexión habitual, y no es fácil ver qué utilidad puede tener para que "otro mundo sea posible". Pero personalmente, no lo pienso así. Un Dios "misterio" no ofrece recetas ni modelos concretos para cambiar la realidad, evidentemente, con lo cual quedamos remitidos a buscar nosotros dar forma al trabajo, la lucha y la 
utopía. Pero ofrece una como "reserva" inexhaurible, de la que se puede echar mano, una y otra vez, para encontrar nuevos rumbos. $Y$ es instancia inapelable, por lo que no se puede poner condiciones a la tarea a favor de "un mundo otro". El misterio, lo último, es lo que otorga radicalidad, ultimidad a lo penúltimo. Exige y posibilita no pactar con lo concreto, sino mantenerlo siempre abierto al más; no ceder al cansancio, sino seguir siempre caminando. Y no es éste pequeño beneficio para quienes se embarcan en la aventura de "un mundo otro".

\section{El mirar del Theos a las "víctimas"}

Ante la problemática de este foro, pienso que el Dios de la tradición bíblico - jesuánica propicia dos cosas fundamentales: una forma de mirar al mundo real y una forma de dejase afectar por él. Lo primero puede configurar la inteligencia, y así ver a las víctimas en el centro de la realidad objetiva. Lo segundo puede configurar la voluntad y poner así la compasión en el centro de la subjetividad. Ambas cosas están en el origen de la tradición bíblica: "Bien vista tengo la aflicción de mi pueblo, y he escuchado el clamor que le arrancan sus capataces, pues ya conozco sus sufrimientos. He bajado a liberarlos" (Ex 3, 7-8).

Mirar a víctimas y reaccionar con compasión son "contenidos" fundamentales del Theos, y pueden resumir el aporte fundamental de la teología a "un mundo otro" - aunque habrá que tener presente otros muchos. Ambas cosas pueden parecer muy simples, pero no lo es aceptarlo y mantenerlo sin condiciones.

\subsection{El encubrimiento}

Hablar de "mundo", sin más, no es suficiente. Hay que poner los ojos en el mundo "real". Pero la teología nos pone en guardia de que, aunque no lo parezca, ver el mundo tal cual es no es nada fácil. No lo es, ciertamente, ver un mundo de víctimas, y la teología da la razón. Juan dice en su evangelio $(8,44)$ que "el maligno es asesino y mentiroso" - y por ese orden. Construir "un mundo otro" es, entonces, difícil, pues hay que construirlo dialéctiamente en contra del maligno asesino. Pero además hay que construirlo en contra del maligno encubridor: el asesinato queda encubierto.

Esta es una verdad de siempre y actual. Sobre el mundo de las víctimas se cierne un gigantesco cover up. Lo he dicho muchas veces. El $11 \mathrm{~S}$ es conocido, pero el 7 O no lo es. E1 7 de octubre de 2001, un mes después del atentado contra las torres de Nueva York, una gran coalición de países democráticos bombardearon Afganistán. Pero Afganistán, pobre, víctima, no tiene calendario, no tiene nombre, no existe, no es. Y así muchas otras aberraciones, como la guerra del coltán en el Congo. El encubrimiento (la violación del octavo mandamiento, no mentir) sobreviene como por necesidad a la depredación y el asesinato (violación del séptimo y quinto mandamientos que producen víctimas). 
El Theos funge como exigencia inapelable a desenmascar el silencio y el encubrimiento. "¡Ay de los que llaman día a la noche y noche al día!”, decía Isaías en nombre de Dios. Y Pablo: "la cólera de Dios se revela contra los que oprimen la verdad con la injusticia" (Rom 1, 18). Y saca las consecuencias: la realidad encubierta ya no trasparenta su verdad más honda y el corazón se entenebrece. Caminamos hacia la deshumanización.

\subsection{El desenmascaramiento de los ídolos}

"Un niño que muere de hambre hoy, muere asesinado", dice Jean Ziegler, relator de la ONU para la alimentación. Las palabras "asesinado" y "hoy" no son artificio literario, sino términos analíticos: las víctimas son producidas por estructuras. Es bien sabido, y no vamos a detenernos en ello. Pero sí en la divinización de esas estructuras, sobre lo que la teo-logía sabe -o debiera saber.

Hubo un tiempo en que exegetas europeos, como von Rad y José Luis Sicre, teólogos como Juan Luis Segundo y Ellacuría, obispos como Monseñor Romero y los que estuvieron en Puebla, vieron la realidad permeada de ídolos, y los denunciaron. Hoy casi no se habla así en el mundo eclesial, y ciertamente no en la sociedad civil. Tampoco creemos que la teología lo tome muy en serio.

Que los ríos, el sol, la luna, en sí mismos expresiones de vida, sean venerados como divinidades, en definitiva no tiene por qué expresar idolatría en sentido estricto, sino que pueden expresar disposiciones antropológicas de venerar fuentes de vida. Sí es sîmbolo de idolatría el dios Molok. Como él, ídolos son hoy realidades históricas existentes, que exigen víctimas para subsistir. Mons. Romero mencionaba en su tiempo la idolatría del capital absolutizado y de la seguridad nacional. Su lenguaje no era metafórico, sino estrictamente racional: son ídolos porque exigen víctimas. Y aun defendiendo y apoyando a las organizaciones populares, también les avisaba de no convertirse en ídolos, absolutizándose a sí mismas y haciendo a otros víctimas, al exigirles lo que va más allá de la justicia y la dignidad humana, o usarlos para esos fines.

Irónicamente, no son los llamados pueblos primitivos los que dan culto a los ídolos, sino las sociedades basadas en el capitalismo, bien sea el occidental, ahora globalizado, o antiguamente el socialista. Y este recordatorio es importante en un mundo secularizado, que se jacta de no estar ya contaminado por lo religioso. Por ser secular, no pensará que la idolatría sea problema suyo. Y la violencia, con sus víctimas, provendría de las religiones. Pero la verdad es más compleja, y en buena medida la contraria: la idolatría pertenece en directo al ámbito histórico secular, y en ese ámbito (capital, poder, armamento) es donde medra más.

Digamos para terminar este apartado que, junto al de los ídolos, es muy importante volver a otro lenguaje largamente olvidado: el imperio. Con la caída de Berlín sólo queda una superpotencia, Estados Unidos. Se autocomprende y actúa 
como imperio, lo cual concibe, además, como su "destino manifiesto" —blasfemia cuando ese destino se remite a Dios (como se hace en Washington). Pero para juzgar sobre el imperio de nuevo viene en nuestra ayuda la teología. Decía Agustín: imperium est magnum latrocinium.

Para ver y denunciar ídolos e imperios no se necesita teología. Evidentemente. Pero, dada la tibieza ambiental de la denuncia, la teología puede ayudar. Y si se me permite lenguaje retórico, "el Theos puede hablar de tú a tú a los ídolos", también hoy. Puede juzgarlos y condenarlos con radicalidad. Y a ello no se atreven democracias, ni gobiernos, ni partidos.

\subsection{Testigos: los profetas}

En algunas religiones, además de textos sobre el Theos hay testigos. Son los "hombres de Dios", como se decía antes. Indudablemente no sólo ellos, sino también personas ajenas a la religión, pueden desenmascarar y denunciar un mundo de víctimas. Pero los "hombres de Dios" ya han mostrado su eficacaia para "destruir y construir", como decía el profeta Jeremías. Ahora, aun en un mundo más secularizado, sus palabras conservan todavía un tono especial, distinto a las del PNUD, por ejemplo, por venerables que sean por otros capítulos. La razón está en que el profeta habla con una radicalidad no usual. Habla "en nombre de Dios". Si se quiere, en nombre de lo último.

Estos "hombres de Dios" pueden hacer despertar del sueño dogmático en que está dormido el mundo de abundancia, democrático o no. Antonio Montesinos lo conminó en 1511, ante la crueldad de los encomenderos con los indígenas de La Española: “¿Éstos no son hombres? ¿No tienen ánimas racionales? ¿Cómo estáis en sueño tan letárgico dormidos?". Y como están las cosas, volviendo a Kant, parece más difícil despertar de este sueño de cruel inhumanidad que del sueño dogmático que exigía el filósofo. El Theos sigue en vela sobre su creación, y hace esas preguntas.

También hacen sospechar, como los antiguos "maestros de la sospecha", de la maldad que se esconde tras la aparente bondad. Tras la globalización, un mundo "globo" (lo que para Platón simbolizaba la perfección), y por causa de la globalización, lo que existen son "vencedores y vencidos".

Desenmascaran que la democracia no es sólo limitada e imperfecta, sino que esconde cosas más graves. "Lo que busca el manejo ideologizado del modelo democrático no es la autodeterminación popular respecto del modelo político y económico, sino el encubrimiento de la imposición capitalista", decía Ellacuría.

Ilustran sobre los "demonios de nuestro tiempo", que se esconden en la sociedad y en las iglesias. Se revisten de buen vivir, y se glorían de haber alcanzado el camino o la utopía de la felicidad. Demonios son el docetismo, vivir en irrealidad, en la abundancia y la pompa, en un mundo que se muere de hambre - lo 
que añade injuria a la irrealidad. El gnosticismo, buscar salvación en lo esotérico para iniciados, y no en el seguimiento de Jesús. Ideologías light, y también una fe y una liturgia light, cuando lo que exige la realidad es un pensamiento y una fe recia. En conclusión, los "hombres de Dios" hacen sospechar que, ante el Cristo que se ha hecho presente en el tercer mundo, como en un ingente Mateo 25 , decimos como el gran inquisidor: "Señor, no vuelvas".

En presencia de las víctimas la palabra de "los hombres de Dios" es inconfundible. Dijo Monseñor Romero la víspera de su asesinato:

"Hermanos, son de nuestro mismo pueblo, matan a sus mismos hermanos campesinos, y ante una orden de matar que dé un hombre, debe de prevalecer la ley de Dios que dice: no matar... Ningún soldado está obligado a obedecer una orden contra la ley de Dios... En nombre de Dios, pues, y en nombre de este sufrido pueblo cuyos lamentos suben hasta el cielo cada día más tumultuosos, les suplico, les ruego, les ordeno en nombre de Dios: jcese la represión!".

Lo que hemos dicho puede ocurrir sin "hombres de Dios" y sin "un Dios de esos hombres". Pero todavía hoy el Theos, con testigos como Romero y Munzihirwa, tiene una fuerza especial para remitirnos a la realidad de las víctimas - quizás una fuerza mayor que cualquier otra todavía hoy. En cualquier caso, no hay que desdeñarlo al pensar y hacer "un mundo otro".

\section{La "compasión" del Theos}

Hemos dicho que el maligno es mentiroso, y los profetas desenmascaran la mentira. Pero es ante todo asesino, y por ello hay que generar vida en contra de la muerte. Dado lo que se busca en un Foro Social lo más crucial de la lucha por la vida puede ser descrito con el término justicia. En ello insiste la teología de la liberación, y el Theos lo exige del hombre religioso: "Hacer justicia, ¿no es eso conocerme?" (Jer 22, 15s). En lo que queremos concentrarnos ahora es en la raíz de esa justicia: la compasión ante las víctimas, lo que es central en el mismo Dios: "He visto sus sufrimientos. Y he bajado a liberarlos y subirles a una tierra buena y espaciosa". Víctimas y compasión son correlativos.

En "un mundo otro" la compasión tiene que ser justicia, y en ello hay que insistir pues se la quiere sustituir de mil maneras - entre otras razones para que la busca de ese "mundo otro" no duela, ciertamente a los que no quieren cambiar. Pero es bueno recordar también la otra dirección: la justicia es una forma de compasión primordial ante todo un mundo de víctimas. Y una justicia, con esas raíces, queda configurada de una manera especial.

La justicia, en efecto. no busca rehacer algún tipo de equilibrio metafísico. No es fidelidad a un absurdo imperativo categórico: fiat iustitia, pereat mundus. Ni siquiera es sólo un medio para superar un conflicto violento - opus iustitiae 
pax - por importante que esto sea. La justicia es la forma que toma la compasión ante unas víctimas que son pueblos oprimidos. Con esto queremos decir dos cosas. La primera es que, por ser forma de la compasión, la justicia es exigida con ultimidad. Y la segunda es que, por ser compasión, genera una mistica que configura muchos aspectos de la vida personal y social. Y aunque el lenguaje no sea lo decisivo, usaremos en adelante el término "misericordia", pues es más usual que el de "compasión" al tratar este tema.

\subsection{La ultimidad de la misericordia}

Alrededor de la primera instrucción vaticana sobre la teología de la liberación, en 1984, surgió un debate importante sobre Dios, que continúa hasta el día de hoy. En la instrucción se explicaban las palabras del éxodo sobre liberación en el sentido de que Dios quería liberar a un pueblo oprimido de modo que llegase a ser su pueblo escogido para darle culto. Pero Juan Luis Segundo e Ignacio Ellacuría insistieron en que no es ésa la exégesis adecuada. En el éxodo la voluntad de Dios es, en directo, liberar esclavos y darles vida. Y la razón para ello es que Dios queda afectado por sus sufrimientos con ultimidad. A esa reacción llamamos misericordia.

Misericordia es, entonces, la reacción ante el sufrimiento de víctimas por el mero hecho de que existe el tal sufrimiento. No hay nada anterior ni posterior que fuerce a ello. Lo muestra la tradición del éxodo y la tradición jesuánica, como lo dejó muy en claro Albert Nolan, en medio del sufrimiento de los negros marginados, en su conocido libro Jesús antes del cristianismo. Es la reacción de Jesús a la repetida petición: "Señor, ten misericordia de mî", lo que la Carta a los Hebreos considerará una dimensión constitutiva del mediador. Y así actúa el buen samaritano de la parábola. Jesús lo menciona para ilustrar el cumplimiento del segundo mandamiento. Pero el samaritano, presentado por Jesús como el ser humano cabal, no actúa por cumplir un mandamiento, sino simplemente porque "se encontró con una víctima en el camino". El sufrimiento del herido le llegó hasta el fondo de su ser, las entrañas, lo último, splajnon. Y se le removieron las entrañas, splajnizomai.

La misericordia puede ir acompañada de sentimientos, pero es más que un sentimiento. Lo que sí hay que hacer, para no desnaturalizarla, es historizarla según sean las víctimas. En un Foro Social Mundial hay que hablar de misericordia como justicia, liberación, redención, humanización, pues es todo un mundo lo que debe ser sanado. Pero también es importante comprender todo ello como formas de misericordia. Si se tienen en cuenta ambas cosa, el trabajo por la justicia recobra una ultimidad y una hondura inigualable. Pero además, exige también delicadeza, cariño, ternura incluso - todo ello medido no necesariamente por sentimientos, sino por aquel espíritu de fineza que decía Pascal, y en lo que de diversas formas insiste Leonardo Boff. Y así, no se divorcian vida y dignidad de las víctimas. 
Como forma de misericordia, la justicia no tiene límites, como no los tiene el amor. Puede exigir el darlo todo, hasta la vida. Y esta ultimidad de la misericordia se comprende con mayor hondura si nos fijamos no sólo en que existe un sufrimiento, sino en que existen víctimas sufrientes - lo cual es más que un juego de palabras. Sus rostros son inintercambiables, cada uno de ellos con una historia única. El sufrimiento afecta, sin duda. Pero las víctimas, además, interpelan sin que nada pueda neutralizar la interpelación. En las conocidas palabras de Metz, no hay nada más allá de "la autoridad de los que sufren" — y en lo personal pienso que la ultimidad aquí implicada nos puede introducir también, mistagógicamente, en la ultimidad de Dios.

\subsection{La mística de la misericordia}

Ante las víctimas, hay que hacer muchas cosas y con mucha seriedad. Pero además, y dado como hoy está el mundo, hay que desarrollar una mística que nos configure personal y, en lo posible, ambientalmente, que es exigida y posibilitada, a la vez, por la misericordia. Lo que ahora queremos recordar es que con esa mística se pueden superar males recurrentes en la Iglesia y la sociedad.

La misericordia hacia las víctimas lleva por sí misma a la inserción en su mundo real. Es la superación del docetismo, vivir en la irrealidad, lo que es principio de deshumanización. En las víctimas hay una invitación, indefensa, a que las ayudemos, pero también a ser nosotros reales, sea en forma de inserción directa o en otras: ser y trabajar para ellos, esperar y gozar como ellos, desvivirse y entregarse por ellos, y a encontrar en ello salvación. Decía Mons. Romero: "Me alegro hermanos de que nuestra iglesia sea perseguida. Sería muy triste que en un país donde hay tantos asesinatos, no hubiese sacerdotes asesinados. Es la verificación de que nuestra iglesia es cristiana y salvadoreña". Son palabras límite, pero sin hacer realidad algo de lo que expresan, con todas las analogías del caso, seguiremos en el docetismo, no sólo el cristológico, sino el eclesiológico y sobre todo el docetismo humano: vivir en un mundo irreal, sea capitalista o socialista, cristiano o musulmán, ladino o indígena... Y no podremos repetir el "me alegro, hermanos", tan importante en medio de cierta tristeza y malestar ambiental. Esa inserción es producto de la misericordia.

La misericordia lleva por sí misma a superar la gnosis, como si la salvación fuera formalmente cosa de conocimiento, no de amor, y cosa de iniciados, es decir, de distanciados. Querer vivir la salvación no gnósticamente, sino con otros, con las víctimas, es producto de la misericorida.

Y también empuja a superar el pensamiento light, como si vivir y creer no fuesen cosas de gente recia. Vivir humanamente supone estar a la altura de una realidad, que es recia en su tragedia y en su exigencia. Y nada hay más recio que las vîctimas. "La liberación sin dolor", "un mundo otro" sin muchos costos, en el que todos salen ganando, es una especie de invención —o ilusión- moderna. 
Expresará filantropía ego-céntrica, pero no proviene de la misericordia ante las víctimas.

La misericordia, por último, porque no se fija universalmente en "todos", sino parcialmente en los "empobrecidos", empuja a conceptualizar la utopía de manera adecuada: utopía es la vida, digna y justa, en fraternidad, de los pobres; abierta, entonces sí, a todos. No se trata de la utopía de Platón en La República, o la de Tomás Moro - tampoco la del paraíso terrenal. Y no es, por supuesto, la vida escandalosa del uno o dos por ciento de la humanidad. Y algo muy importante: la misericordia hace que esa utopía de los pobres no se comprenda existencialmente como ou-topía, aquello tan perfecto para lo que no hay lugar, sino como eu-topía, aquello tan necesario para lo que tiene que haber lugar.

\subsection{Testigos: los mártires}

El Theos de la misericordia tiene también sus testigos, los seguidores de su Hijo misericordioso. En nuestro mundo esos testigos por antonomasia son los mártires, hombres y mujeres, de misericordia consecuente, total, hasta el final. En muchos lugares del tercer mundo ha habido innumerables testigos, y me parece absolutamente central recordarlos en este Foro Social, como elemento acompañante en la liturgia, sí, pero sobre todo como luz para lo que se pretende conseguir y cómo se quiere conseguir.

Los mártires nos han mostrado un camino que nosotros tenemos que recorrer. Y como lo muestra la experiencia, no necesariamente la mera razón, se convierten en motivo de esperanza y de gratitud. Verifican en nuestra época la sentencia de Tertuliano: "la sangre de los mártires es semilla de nuevos cristianos". En nuestras palabras, los mártires de la misericordia expresan que es posible luchar por "un mudo otro", y que esperan que "otro mundo es posible". Y junto a ellos, y con prioridad lógica, aunque no lo tratemos ahora, hay que recordar la ingente nube de testigos, millones de mártires sin nombre, los pueblos crucificados.

Esta mística de la misericordia es una forma de ser, hecha de amor, y con características específicas: dialéctica, parcialidad, inserción, humildad. De ella, con un más y un menos, se diga en lenguaje o se mantenga anónima, debe estar transido el Foro Social Mundial. Y el Foro de Espiritualidad debe ayudar a ello. El Theos - ciertamente el de Jesús - es guardián de esa mística. Como hemos dicho repetidas veces, él mismo, la transcendencia, se ha hecho transdescendencia para llegar a ser condescendencia.

\section{El "misterio" del Theos}

Hemos comenzado recordando palabras de K. Rahner sobre el misterio de Dios. Dios es mayor, Deus semper maior, a lo que añade una novedad escandalosa: el Dios menor, Deus semper minor. En palabras sencillas podemos decir, el 
Dios inabarcable, inmanipulable, y el Dios abajado, empequeñecido — hasta la cruz. No es ahora el momento de profundizar en el tema, y ya hemos dicho que no suele hacerse en foros como éste. Pero quisiera hacer dos reflexiones muy breves que puedan ayudar a profundizar el trabajo por "un mundo otro".

La primera tiene que ver con nuestra subjetividad. Trabajar por "un mundo otro" es cosa exigente y arriesgada, y no es fácil mantenerse en ello. Por la magnitud de la tarea exige perseverancia, aceptar el "a la larga", la antigua disposición a "votos perpetuos". Exige seriedad, entrega y generosidad. Y en principio, sin límites, como se enfatizaba antes entre los abundantes mártires que ofrecieron todo por la liberación de sus gentes - y de lo que hoy se habla menos. No hay que caer en masoquismos, pero ya he expresado el temor que me produce este silencio, como si se hubieran encontrado caminos de una "liberación sin dolor", que antes hemos comentado.

Pero a eso, que es conocido, hay que añadir que ese trabajo tampoco es inmune a las limitaciones y pecados de todo lo humano. Sin embargo, no suele haber examen de conciencia sobre ello. Se evalúa la organización de los foros y de las tareas a realizar. Pero no se examina la pecaminosidad en la tarea. Y no sé si solemos hacerlo los teólogos con nuestra teología.

$\mathrm{Y}$ ahora viene la reflexión. Al combatir la opresión que producen otros, no hay que hacerlo con prepotencia ni arrogancia. Y no sólo eso. Hay que preguntarse por uno mismo, por lo que también hacemos o hemos hecho mal. Al liberar, no hay que caer en arrogancia. Y por ello "hay que hacer la revolución como un perdonado", lo que le oí a González Faus hace treinta años.

El trabajar por "un mundo otro" lleva el lastre de todo lo humano: incoherencias, facilismos, personalismos. Sólo que para verlo así, hay que ir al fondo de nosotros mismos. No es fácil. Queda la conciencia, ciertamente. Pero el creyente puede, con Agustín, pensar en el Deus intimior intimo meo, ese misterioso Dios, y bucear donde pocos quieren hacerlo. Y queda el Espíritu, que nos libera de nosotros mismos, como nos enseñó Pablo. Es el Deus semper maior.

Dejamos para el final una reflexión, que puede ser la más fundamental: el misterio de Dios y el misterio de los pobres, en su realidad, se remiten mutuamente ${ }^{1}$. El Deus semper minor. Para nosotros, que no somos pobres porque damos la vida por supuesto, la realidad del pobre no se agota en lo categorial. Percibimos en ellos un "menos", que se nos puede mostrar — opthe - como un "más" especial. Con todas las analogías del caso, se muestran afines al misterio de Dios. Y sobre eso queremos decir una palabra.

1. En este apartado retomamos lo que escribí en "Epílogo", José María Vigil (org.), Bajar de la cruz a los pobres: cristología de la liberación, 2a. edición, 2007. 
En primer lugar, la ultimidad del pobre. En el Exodo "Dios" y "pueblo sufriente" son realidades últimas, y don Pedro Casaldáliga nos lo acaba de recordar: "todo es relativo menos Dios y el hambre". Y ambas realidades no son últimas y absolutas cada una de ellas por separado, sino en mutua relación, en lo que creo que consiste la originalidad de nuestra fe. Grande es la tentación a separarlas o a mantenerlas a una distancia prudencial, pero siempre resurge la intuición original. Mons. Romero lo expresó parafraseando una conocida sentencia: "gloria Dei vivens pauper", que concreta y va más allá de la formulación universal, original de Ireneo: "gloria Dei vivens homo".

En segundo lugar la sacramentalidad del pobre. Existe una larga tradición de la dignidad de los pobres basada en su sacramentalidad con respecto a Dios y su Cristo. Según Mateo 25, con ellos se ha querido identificar Cristo de manera especial. En la Edad Media eran llamados "vicarios de Cristo". Puebla dice de ellos que, independientemente de su situación personal y moral, Dios los "defiende y los ama", y por ese orden.

En tercer lugar la sacramentalidad, mayor, de su crucifixión, lo que merece una reflexión especial. Los pobres son los empobrecidos, y muchos de ellos mueren -lenta o violentamente - por serlo. De hambre mueren cien mil personas al día, y cada siete segundos un niño de menos de diez años. La cruz es, pues, todo menos metáfora. Significa muerte y crueldad, a lo que - como en la cruz de Jesús- con frecuencia se añade inocencia e indefensión. A los teólogos cristianos la cruz nos remite a Jesús de Nazaret. El es el crucificado. Por eso, al llamar a los pobres de este mundo pueblo crucificado se les saca del anonimato, pero además se les otorgar máxima dignidad. "Ustedes son el divino traspasado", dijo Monseñor Romero, a campesinos aterrorizados, sobrevivientes de la masacre de Aguilares. El misterio de los crucificados es la presencia del misterio de la cruz de Jesús. La cruz de víctimas inocentes e indefensas es el sacramento del Deus minor.

Para los creyentes es esencial también ponernos ante los pueblos crucificados, como san Ignacio de Loyola pedía al ejercitante, cuándo éste se reconocía como pecador. Le pedía que se hiciese tres preguntas ante el crucificado: "qué he hecho, qué hago y qué voy a hacer por Cristo". Entre nosotros - historizando esta tradición - nos preguntamos "qué hemos hecho para que nuestros pueblos estén crucificados, qué hacemos para bajarlos de la cruz y que vamos a hacer para resucitarlos". No hay aquí hybris de ninguna especie. Hay reconocimiento de nuestro pecado, hay expresión humilde de conversión y hay decisión, agradecida, de salvar. No es poca cosa que nos pidan ponernos ante los crucificados para poder ponernos - de verdad - ante Dios.

Y hay que añadir algo importante y olvidado. Bajarlos de la cruz no es sólo compasión, opción por los pobres. Es devolver a los pobres un poco de lo que ellos nos dan. Sin saberlo, por lo que son y muchas veces por los valores que poseen, nos salvan, nos humanizan, nos perdonan. Al cargar nosotros con su rea- 
lidad, una pesada cruz, nos sentimos cargados por ellos. Hemos escrito que extra pauperes nulla salus ${ }^{2}$. Son bendición.

Un Theos, cuyo sacramento son los pobres y cuya gloria es que el pobre viva, bien puede estar presente en un foro mundial social. Da ultimidad última a los pobres. Y para los creyentes, el "gloria Dei vivens pauper" bien puede ser una "fórmula breve del cristianismo.

\section{A modo de apéndice. El ecumenismo religioso en un Foro Social Mundial}

Para terminar, hagamos una breve reflexión sobre el ecumenismo religioso, que estos foros propician y que es tan beneficioso para conseguir "un mundo otro".

Comienzo con una experiencia de estos días. Nairobi y El Salvador están a miles de millas de distancia. Raro es que sus pueblos se conozcan, y sin embargo, algo los une en la realidad. En una escuelita de Kibera, una niña me dijo: “¿El Salvador? La tierra de un obispo". No conocía los detalles, pero se refería a Monseñor Romero. Un compañero jesuita de la República Democrática del Congo me habló de una tesis doctoral, escrita en la Universidad de Lovaina en el 2004, con el siguiente título: “El obispo Munzihirwa, ¿el Romero del Congo?”. Munzihirwa, muy parecido a nuestro Monseñor, fue asesinado en 1996. En la clausura del Foro de Teología, cuando salía del edificio, pude saludar brevemente a Desmond Tutu. Le agradecí su ponencia, y sólo añadí que venía de El Salvador, la tierra de Monseñor Romero. “ ¿Romero? He inspired us”, dijo con total convicción. Nuestro Monseñor, salvadoreño y católico, estuvo muy presente en Kenia y en la Sudáfrica anglicana.

Sin conocerse, Desmond Tutu y Oscar Romero, llegaron a ser hermanos muy cercanos. Lo fueron con naturalidad y sin dejar su Iglesia ninguno de ellos. Y lo que más me interesa recalcar es que no los hermanó mínimos comunes, sino máximos: el gran amor por sus pueblos oprimidos, y la disposición a darlo todo por su liberación. Lo que me interesa es la conclusión: lo que hace connatural el ecumenismo es aquello que más nos hace a todos hijos e hijas de Dios, la compasión a las víctimas, el amor. Nos unimos en lo que es más, no en el que es menos.

Y eso, pienso yo, puede ocurrir entre las religiones, aunque, evidentemente la complejidad es aquí mucho mayor que en el ecumenismo entre iglesias cristianas. Tampoco soy experto en estos temas y menos en religiones africanas, y sólo puedo ofrecer reflexiones sencillas, basadas en intuiciones. Expertos habrá que juzguen si están o no bien encaminadas.

Pienso que el diálogo interreligioso no tiene por qué estar basado, a como dé lugar, en algo que sea común a todos, aunque para ello haya que contentarse con mí-

2. Véase mi libro Fuera de los pobres no hay salvación. Pequeños ensayos utópico-proféticos, Madrid, Trotta, 2007. 
nimos. En lo personal, este modo de proceder me parece peligroso, pues se pudiera terminar en un ecumenismo de religiones, sin vigor para buscar "un mundo otro". Podremos estar de acuerdo, pero lo acordado será demasiado poco y muy débil para revertir este mundo.

El dinamismo de la comunión entre religiones pienso que puede tomar otro rumbo: que cada religión profundice en lo suyo propio, en lo mejor que tiene y en lo que piensa que más va a transformar a este mundo enfermo. No sé cuánto ecumenismo podrá generar esta actitud en la superficie visible de las cosas, pero el ecumenismo que resulte estará basado en la hondura de lo religioso. Y esperamos que allí, en esa hondura, se dé convergencia de muchos, ojalá de todos.

En lo personal no veo en qué puede dificultar al ecumenismo religioso el profundizar en Jesús de Nazaret, o en el hinduísmo de Gandhi, o en el Buda... Mi esperanza es que las religiones coincidan en lo profundo: la mirada a un mundo de víctimas y la reacción de compasión. Y que cada una de ellas aporte sus matices, saberes, espiritualidades, a enriquecer ambas cosas. Desde el cristianismo ofrecemos una constelación de realidades centrales, como reino y Dios, profecía y utopía, praxis y gracia, fe personal y vida en comunidad...

Esta esperanza es otra forma de expresar la fe cristiana: cuando escarbamos en lo más hondo todos nos encontramos con "víctimas", con un "Theos" cuya gloria es que tengan vida, y con una "exigencia ética" a bajarlas de la cruz, y llegar así a ser todos "familia humana". La convicción de la fe es que es verdad. Y que alrededor de esos mínimos-máximos nos podamos congregar todos.

El ecumenismo de las religiones no es simplemente encontrarnos todos en algún lugar, sino encontrarnos haciendo, esperando y rezando a Dios por la salvación, la redención y la humanización que el mundo necesita. Y pienso que esto ocurre cuando cada una de las religiones, y todas en su conjunto, son religiones con vigor, con honradez y con compasión ante las víctimas. Ese ecumenismo es posible y es necesario para hacer "un mundo otro".

No sé qué pensarán sobre lo que acabo de decir los miembros de otras religiones que están aquí presentes. Mi esperanza es que nos entendamos y nos apoyemos. No se trata de imponer a otros el Theos de cada uno, pero sí de buscar - y en mi caso, de desear - que, en el fondo, todos nos encontremos con la misma mirada a las víctimas y la misma compasión para sanarlas. 